\title{
The Canadian Association of Gastroenterology - Are you a member yet?
}

\author{
Pierre Paré MD FRCPC, Chair, CAG Admissions Committee \\ David Pearson MD FRCPC, CAG Admissions Committee \\ Nathalie Vergnolle PhD, CAG Admissions Committee
}

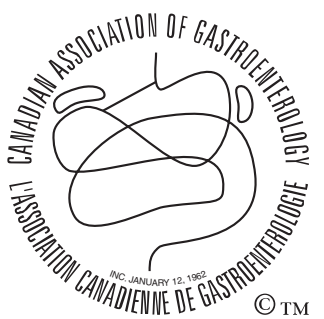

En français voir page 565
Since its inception in 1962, the Canadian Association of $\checkmark$ Gastroenterology (CAG) has grown from a handful of physicians into an impressive and diverse membership of almost 1000 (Figure 1). Remaining true to the philosophy of its founders, the Association is a multidisciplinary organization comprised of gastroenterologists, hepatologists, pediatricians, surgeons, radiologists, internists, clinical and basic scientists, nurses, research coordinators, residents, medical students and representatives of industry. Members share the common goals of supporting and engaging in the study of the digestive tract in health and disease, and promoting the advancement of gastroenterology by providing leadership in patient care, research, teaching and continuing professional development.

If you have an interest in gastrointestinal (GI) health and disease, but are not yet a member, we invite you to join the CAG. Consider these benefits of membership:

\section{Canadian Digestives Diseases Week}

Held each year, Canadian Digestive Diseases Week (CDDW) is an educational event of the highest quality, offering a clinical postgraduate course, clinical and basic science symposia and the latest in Canadian GI research. CDDW's many symposia and paper sessions are accredited as section 1 learning activities, as defined by the Maintenance of Certification Program of the Royal College of Physicians \& Surgeons of Canada (RCPSC). For example, clinicians who attended CDDW 2003 could have claimed up to 28 credits $-35 \%$ of their annual requirement!

Conference registration is free for Regular, Senior, Trainee, and Supporting Members and is only $\$ 250$ for International Members (nonmember rate is $\$ 500$ ). Also free to all registrants is the opening night McKenna reception, lecture and dinner, and buffet lunches and nutrition breaks offered during the conference. Taken all together, CDDW represents a tremendous value for CAG members! Your membership also allows you to provide input on the direction of education within the CAG, by casting your vote on the annual educational needs assessment.
Online educational programs - Free subscription

As a CAG member you can subscribe free of charge to the CAG Interactive Lecture Series. You will receive an updateable CD-ROM that allows you to review audio- and videotaped sessions from CDDW and other national educational events. All lectures meet the RCPSC requirements for Section 4 credits. Use the ever-expanding Lecture Series library to keep current with the latest information.

Receive CAG mailings - Keep abreast of gastroenterology in Canada

As a CAG member you will receive notification of important news and opportunities, such as calls for proposals for grants and research awards. You will also receive a complimentary subscription to the Canadian Journal of Gastroenterology.

\section{Network with colleagues}

The annual CDDW meeting provides an excellent opportunity to collaborate, network and socialize with colleagues in your area of specialty in a relaxed setting outside the office. Can't get time off for CDDW? Look up colleagues in the CAG database, a comprehensive listing of members updated daily, open to Regular, Senior, Trainee and Affiliate/International Members.

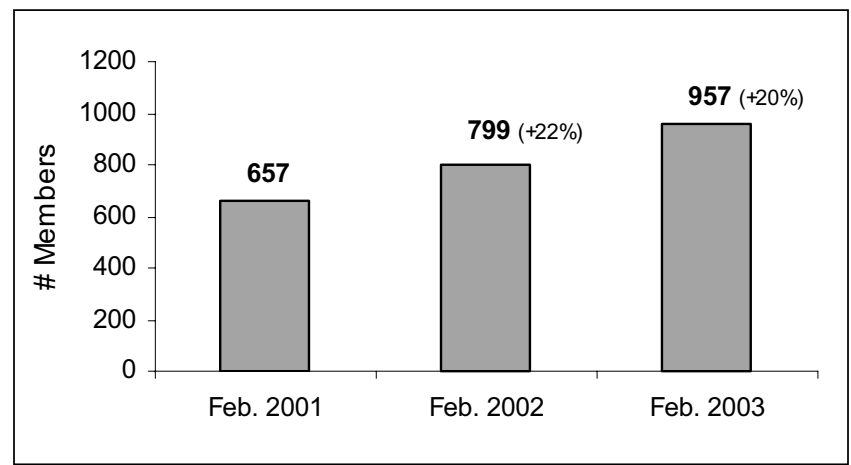

Figure 1) Recent growth in membership of the Canadian Association of Gastroenterology
Abbott Laboratories Ltd.
AstraZeneca Canada Inc.
Axcan Pharma Inc.
Janssen-Ortho Inc. 
Table 1

CAG Membership Categories.

\begin{tabular}{|c|c|c|c|c|c|}
\hline Membership Category & Eligible & $\begin{array}{c}\text { Annual } \\
\text { fee }\end{array}$ & $\begin{array}{c}\text { CDDW } \\
\text { registration* }\end{array}$ & $\begin{array}{c}\text { Voting } \\
\text { privileges }\end{array}$ & $\begin{array}{l}\text { Eligible for } \\
\text { research funding }\end{array}$ \\
\hline Regular & $\begin{array}{l}\text { Physicians, other healthcare professionals } \\
\text { and biomedical scientists }\end{array}$ & $\$ 200$ & Free & Yes & Yes \\
\hline Trainee & $\begin{array}{l}\text { Graduate students, residents, } \\
\text { postdoctoral and research fellows }\end{array}$ & None & Free & No & Yes \\
\hline Senior & Members 65 years of age or older & None & Free & Yes & Yes \\
\hline Affiliate/International & $\begin{array}{l}\text { Physicians, other healthcare professionals } \\
\text { and biomedical scientists outside Canada }\end{array}$ & $\$ 100$ & $\$ 250$ & No & No \\
\hline Supporting & Representatives of industry or government & $\$ 400$ & Free & No & $\mathrm{N} / \mathrm{A}$ \\
\hline
\end{tabular}

${ }^{*}$ Nonmember registration fee is $\$ 500$

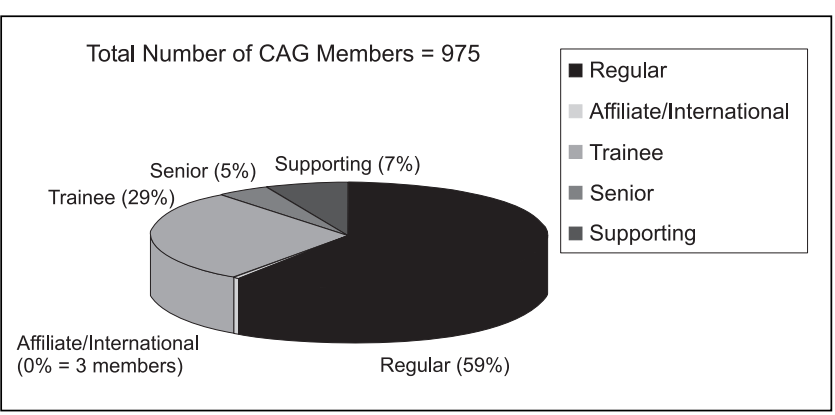

Figure 2) Current membership in the Canadian Association of Gastroenterology (CAG) by category.

Help advance gastroenterological practice and research in Canada

The strength of the CAG is largely due to the support of the membership. As a growing organization of 975 members, the Association is a prominent national body effectively poised to effect change. If you have an interest in the area, why not join the CAG and help shape the face of gastroenterological practice and research in Canada?

\section{BECOMING A MEMBER}

The Association offers five different categories of membership to meet the varying needs and situations of those interested in gastroenterology and GI research. Benefits and privileges of each category are outlined in Table 1. Current membership by category is shown in Figure 2.

Applying for membership is as easy as completing a brief form available from the CAG website (visit www.cag-acg.org and choose CAG Members/New Members) and faxing this to the National Office. Trainee and Supporting membership applications are reviewed by an expedited process, where provisional member status is granted within two weeks. Regular and Affiliate/International membership applications are reviewed by the Admissions Committee on a quarterly basis, with provisional status granted within two weeks of this meeting. Once provisional member status is given, applicants begin receiving all the benefits of membership. Provisional members are then presented for final approval at the Annual General Meeting at CDDW.

If your work or interests are in digestive health and disease but you are not currently a CAG member, we hope you will consider joining the Association. We look forward to welcoming you as our newest member. 


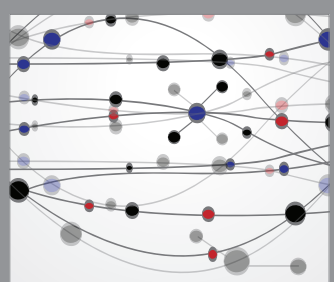

The Scientific World Journal
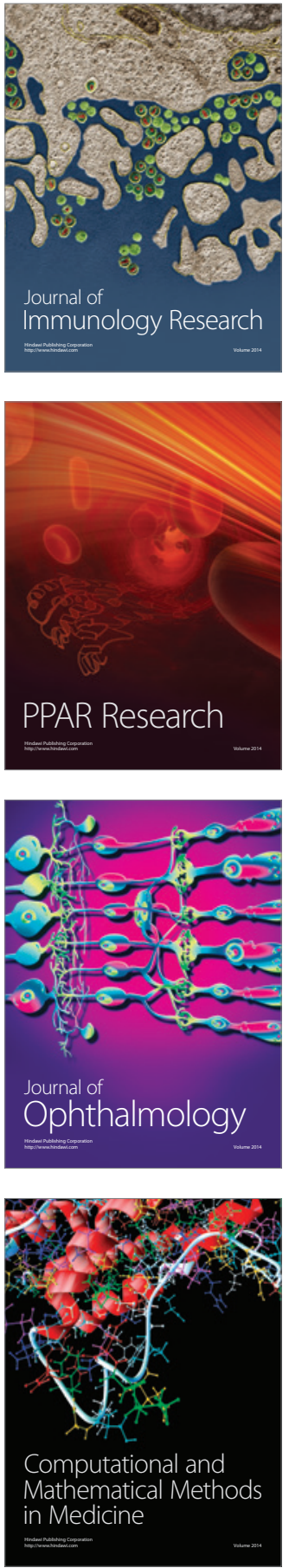

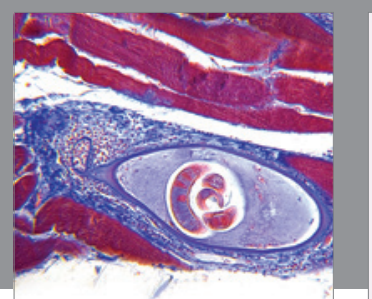

Gastroenterology Research and Practice

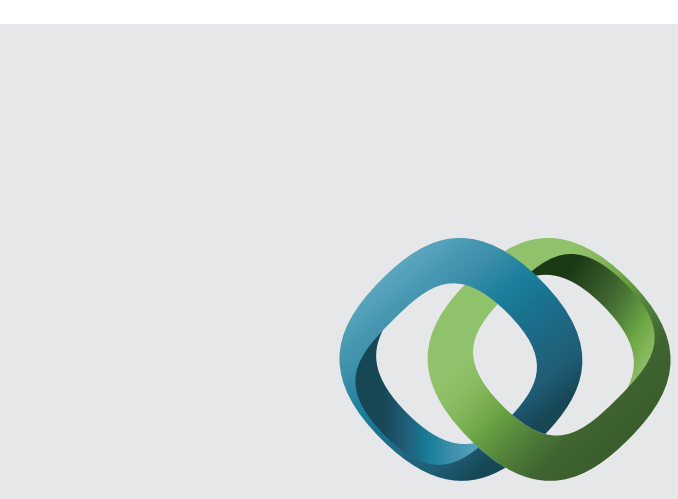

\section{Hindawi}

Submit your manuscripts at

http://www.hindawi.com
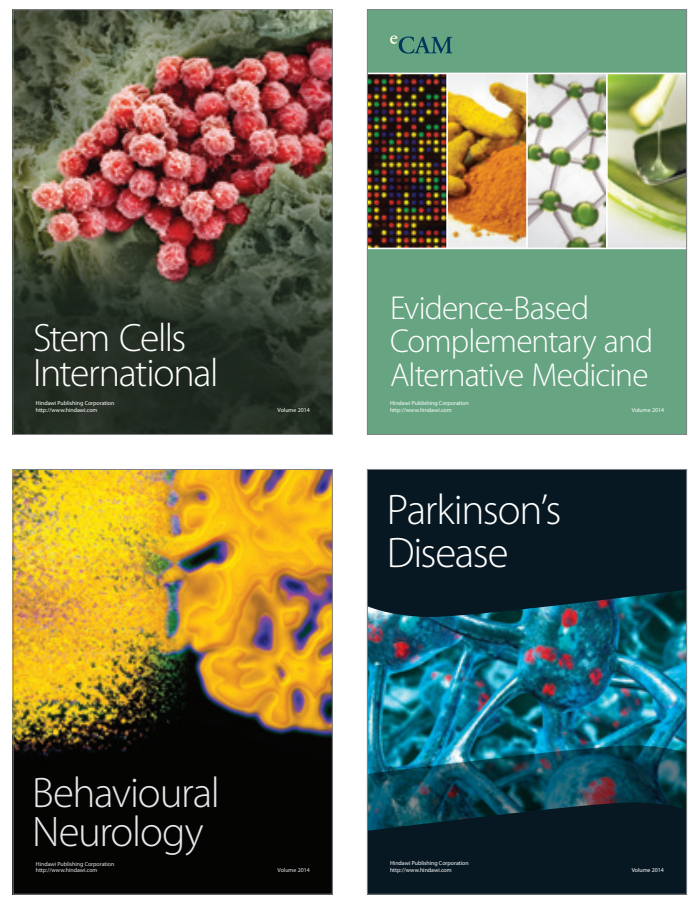
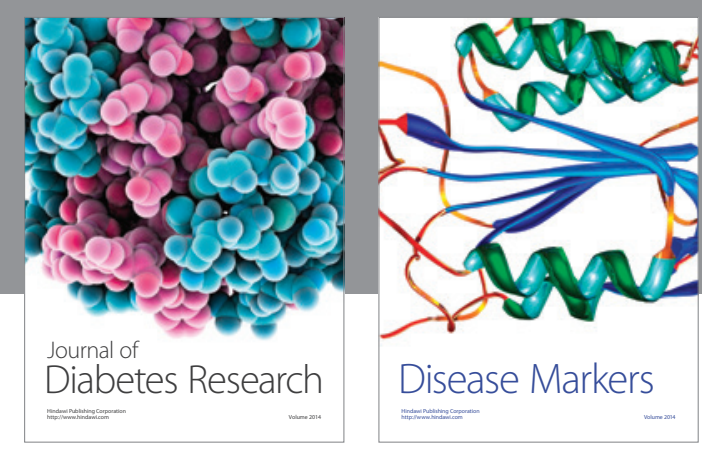

Disease Markers
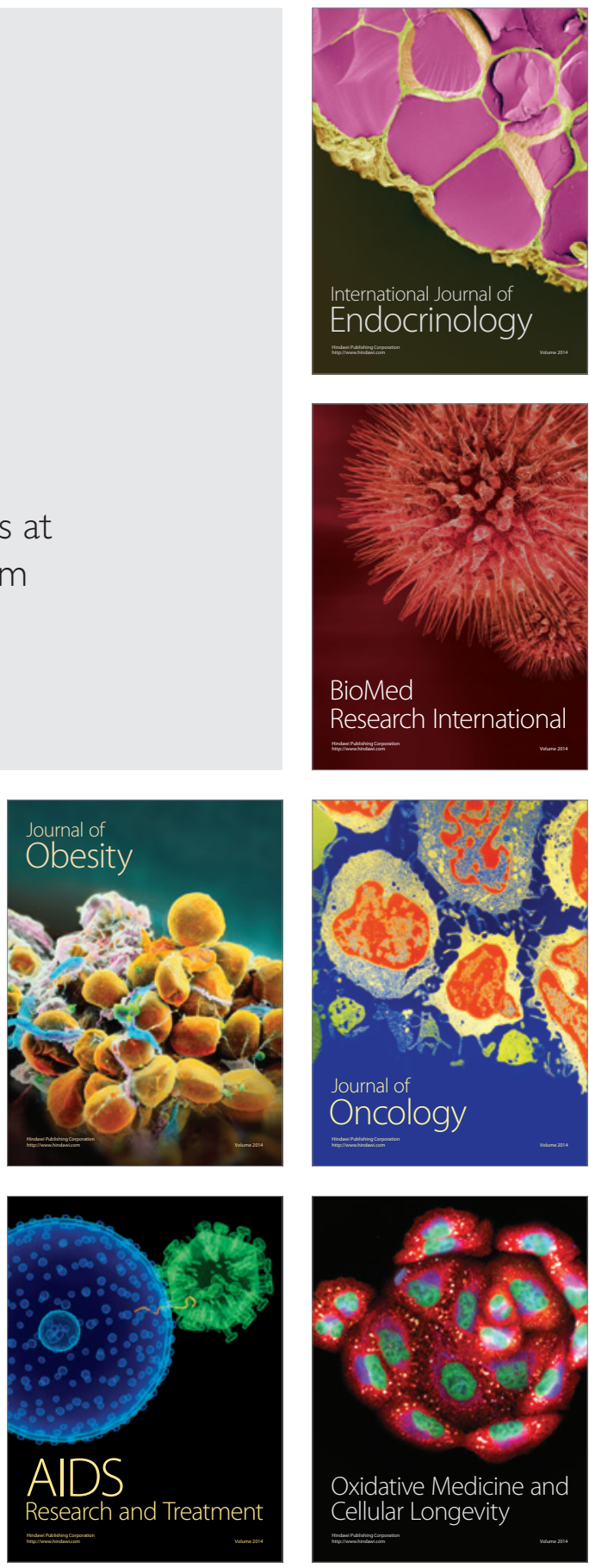